\title{
Frank's Sign as a Predictor of Cardiovascular Disease
}

\author{
Adys Isabel Camacho Ayola ${ }^{1 *}$, Olga Vanessa Manrique Arismendy², Sara Isabel Ramírez Urrea ${ }^{3}$, \\ Tatiana Betancur Pérez ${ }^{4}$, Vanessa del Carmen Angulo García ${ }^{1}$, María Andrea Muñoz Suárez $^{5}$, \\ Mara del Carmen Guerra Jiménez ${ }^{1}$, Mario Enrique Sayas Herazo ${ }^{6}$ and Néstor Miguel Pérez \\ Romero $^{6}$
}

${ }^{1}$ General Medical of the University of Sinú, Colombia

${ }^{2}$ Fourth-Year Medical Student from the Pedagogical and Technological University of Colombia

${ }^{3}$ General Medical of the San Martín University Foundation, Colombia

${ }^{4}$ General Medical from the Cooperative University of Colombia

${ }^{5}$ Intern at the University of Sinú, Colombia

${ }^{6}$ General Medical of the Rafael Núñez University Corporation, Colombia

*Corresponding author: Adys Isabel Camacho Ayola, General Medical of the University of Sinú, Colombia

\section{ARTICLE INFO}

Received: 仹August 07, 2021

Published: 幽 August 17, 2021

Citation: Adys Isabel Camacho Ayola, Olga Vanessa Manrique Arismendy, Sara Isabel Ramírez Urrea, Tatiana Betancur Pérez, Vanessa del Carmen Angulo García, et al., Frank's Sign as A Predictor of Cardiovascular Disease. Biomed J Sci \& Tech Res 38(2)-2021. BJSTR. MS.ID.006118.

\section{SUMMARY}

This systematic review was carried out in order to collect new data to establish the relationship between Frank's sign and the development of cardiovascular disease. It is important to highlight that the Frank sign or diagonal groove of the ear lobe is highly prevalent as a marker of generalized atherosclerosis and obstructive ischemic heart disease, which is related to a greater probability of establishment and development of coronary problems or cerebrovascular accidents.

Keywords: Frank's Sign; Cardiovascular Disease; Diagonal Earlobe Furrow

\section{Introduction}

Cardiovascular disease for many years has represented the leading cause of hospitalization and death worldwide. More people die each year from cardiovascular disease (CVD) than from any other cause. Heart disease includes a wide variety of diseases that affect the heart: blood vessel disease, coronary artery disease, arrhythmias, congenital heart defects, heart valve disease, heart muscle disease, and heart muscle infections. The risk of suffering from cardiovascular disease (CVD) is increased by an unhealthy diet, which is characterized by a low consumption of fruits and vegetables and a high consumption of salt, sugars and fats. An unhealthy diet contributes to obesity and being overweight, which in turn are risk factors for CVD. Ischemic heart disease is the most common coronary heart disease, in general it refers to those conditions that involve the narrowing or blockage of blood vessels, caused by damage to the heart or by underlying pathologies such as atherosclerosis that represents a large rate of morbidity.

It is defined as the accumulation of fatty plaque that thickens and hardens on the arterial walls that usually inhibits the flow of blood through the arteries to organs and tissues, of an asymptomatic initial stage, silent evolution and that occurs with 
sudden death. Among the markers of atherosclerosis, we find the Frank's sign or diagonal groove of the earlobe, also associated with cardiac pathologies such as obstructive ischemic heart disease, cerebrovascular accident, among other coronary problems. Symptoms of cardiovascular disease can be different between men and women, and symptoms can include chest pain (angina), shortness of breath, pain, numbness, weakness, or cold in the legs or arms if they narrow the blood vessels of the parts in the body, pain in the neck, jaw, throat, upper abdomen, or back. Some of the risk factors for developing heart disease can include age, gender, family history, smoking, poor diet, lack of physical activity, alcohol consumption, hypertension, diabetes, and obesity.

\section{Materials and Methods}

A bibliographic search was carried out that spanned from 2017 to 2021 in the databases pubmed, Elsevier, scielo, Update, medline, national and international libraries. We use the following descriptors: Frank's sign, cardiovascular disease, heart disease, diagonal groove of the earlobe. The data obtained oscillate between 16 and 60 records after the use of the different keywords. The search for articles was carried out in Spanish and English, it was limited by year of publication and studies between 2017 and 2021 were used. The main exclusion criteria were articles that had more than 5 years of publication.

\section{Results}

Frank's sign is defined as an anatomical accident that is structurally characterized by an accumulation of collagen fibers that make up a large conjunctive septum that leaves fat clusters without septum, with a superficial capillary plexus of low density, forming a cleft diagonal that begins at the lower edge of the external auricular canal and is directed at an angle of $45^{\circ}$ towards the edge of the ear lobe [1]. This anatomical accident is observed in more than half of the adult population in both sexes, it is generally complete, bilateral, deep and is accompanied by accessory furrows, with the age of the patient its prevalence increases significantly and its morphological characteristics are accentuated. In relation to modifiable cardiovascular risk factors, the bilateral Frank's sign is significantly more prevalent in patients with a history of cardiovascular event than in patients without a history [2].

Atrial lobe cleft is more prevalent after age 50 and is associated with obesity, smoking, and high blood pressure. A genetic basis related to the HLA-B27 system, the C3-F gene for atherosclerosis, and chromosome 11 [3]. Several studies have confirmed the relationship between the cleft lobe sign, cardiovascular disease and ischemic heart disease, which have shown a higher incidence in Caucasian, Chinese and Latino populations and a lower incidence in the Japanese population $[3,4]$. The pathophysiology is not very clear, but the pathophysiological link between Frank's sign and coronary artery disease has been difficult to determine. Anatomically, both the earlobe and the heart are supplied by terminal arteries and without the possibility of collateral circulation, this being a hypothesis. Another suggestion is that the generalized loss of elastin and elastic fibers seen in men by biopsy taken from the earlobes of affected individuals reflects microvascular disease that is also present in the coronary bed $[4,5]$.

\section{Discussion}

In 1973 the American pulmonologist Saunsders T. Frank described the diagonal furrow of the earlobe (Frank's sign) and called it a potential marker of cardiovascular disease. 48 years later, its usefulness continues to generate controversy, the studies published to date remain inconsistent and with disparate results [6]. According to a large epidemiological study directed by Tranchesi in a population of patients with ischemic heart disease compared to healthy controls, the cleft lobe sign is related to the number of damaged coronary vessels with obstruction greater than $70 \%(\mathrm{p}$ $=0.015$ ), with a sensitivity of $65 \%$, specificity of $72 \%$, positive predictive value of $42 \%$, and negative predictive value of $87 \%$ [7].

The most recent study is that of Marta Aligisakis et al, made in Switzerland, with 5064 patients being published in 2016; The objective of this study was to evaluate the associations of Frank's sign with a large panel of cardiovascular risk factors and also with cardiovascular diseases in a sample based on the adult population; finding as a result that Frank's sign is significantly associated with hypertension and a history of cardiovascular disease, independently of other risk factors or potential confounding factors; Within the results, he comments that it is more prevalent in men and that it increases with age and that a possible explanation is the changes in collagen due to aging and smoking. The Frank sign also presented associations between hypertension, glucose level and the history of coronary disease that remained significant after adjusting for body mass index, it also suggests that this sign could be used as a marker of these risk factors [6-10].

\section{Conclusion}

The cardiovascular risk calculated based on contrasted predictive indices (Framingjan equations, REGICOR, SCORE, ASCVD), is significantly higher in patients who have shown diagonal earlobe Swedish (FRANK'S SIGN), especially when it is complete, bilateral, deep and meets accessory grooves. Which leads us to affirm that this anatomical accident should be considered an indicator of cardiovascular risk associated with the natural history of the patient with risk factors for cardiovascular disease and the existence of a history of the same events. 


\section{References}

1. Buller Viqueira Eva, García Junquero Milagros Rocío, Fernández Martínez Diego (2014) Surco diagonal en lóbulo de la oreja: ¿nos alerta ante un posible cardiópata? Rev Clin Med Fam 7(3): 231-233.

2. Kuri M, Hayashi Y, Kagawa K (2001) Evaluation of diagonal earlobe crease as a marker of coronary arterydisease: the use of this sign in preoperative assessment: Earlobecrease sign and coronary artery disease. Anaesthesia 56(12): 1160-1162.

3. CarrilloEsper Raúl, Carrillo Córdova, Jorge Raúl, Carrillo Córdova, Luis Daniel (2010) Signo del lóbulo hendido, ¿curiosidad clínica o marcador de cardiopatía isquémica?; Gaceta Médica de México 146: 225-227.

4. Evrengül Harun, Dursunoĝlu Dursun, Kaftan Asuman (2004) Bilateral diagonal earlobe crease and coronary artery disease: A significant association. Dermatology 209(4): 271-275.

5. Elliott William J, Karrison Theodore (1991) Increased all-cause and cardiac morbidity and mortality associated with the diagonal earlobe

\section{ISSN: 2574-1241}

DOI: $10.26717 /$ BJSTR.2021.38.006118

Adys Isabel Camacho Ayola. Biomed J Sci \& Tech Res

(C) (P) This work is licensed under Creative

Submission Link: https://biomedres.us/submit-manuscript.php crease: A prospective cohort study. The American Journal of Medicine 91(3): 247-254

6. Aligisakis M, Marques Vidal P, Guessous I (2016) Did Dumbo suffer a heart attack? Independent association between earlobe crease and cardiovascular disease. Bmc Cardiovascular Disorders.

7. Marco Antonio Martínez Ríos; Infarto Agudo De Miocardio Documento De Postura; Academia nacional de medicina mexico-Conacyt

8. Lichtstein E, Chapman I, Gupta PK (1976) Letter: Diagonal ear-lobe crease and coronary artery sclerosis. Annals of Internal Medicine 5(3): 337-338.

9. Pasternac A, Sami M (1982) Predictive value of the ear-crease sign in coronary artery disease. Canadian Medical Association Journal 126(6): 645-649.

10. Elliott WJ (1983) Ear lobe crease and coronary artery disease. 1,000 patients and review of the literature. American Journal of Medicine 75(6): 1024-1032.

$\begin{array}{ll}\text { BIOMEDICAL } & \text { Assets of Publishing with us } \\ \text { RESEARCHES } & \text { - Global archiving of articles } \\ \text { - Immediate, unrestricted online access }\end{array}$

